\title{
The study on Yangling farmer profession associations ${ }^{*}$
}

\author{
WANG Zheng-bing ${ }^{1}$, XU Ting ${ }^{2}$, SUN Hao-jie ${ }^{3}$, Allan Rae ${ }^{4}$ \\ (1. College of Economics and Management, Wuhan Polytechnic University, Wuhan 430023, China; \\ 2. Entrepreneurship Commercialization and Innovation Center, The University of Adelaide, Adelaide SA 5005, Australia; \\ 3. College of Economics and Management, Chang'an University, Xi'an 710061, China; \\ 4. Department of Applied and International Economics, Massey University, Palmerston, North 4410, New Zealand)
}

\begin{abstract}
Yangling farmer profession associations are developing quickly. The members of associations account for $11 \%$ of the total peasant households. The speed of the members' income increase is higher three percentage points than the speed of the non-members. However, some problems still exist in the associations, such as the members are not enough much, the mechanism is not sound, the scope of business is small. In order to promote the associations to develop, the authors put forward to improve the one person a ticket system, establish the member funds account, make democratic management sound and let experts guide the associations.
\end{abstract}

Key words: association; democracy; supervise

\section{Introduction}

Yangling is located in Wugong County, Shaanxi province. In 1997, it was approved by the State Department as a state-level agricultural high-tech industries demonstration zone. The region of 94 square kilometers hosts 4 regional rural towns and 71 villages with a total population of 120,000 including an agricultural population of 80,000. In recent years, Yangling demonstration zone has engaged in a range of demonstrations in agricultural science and technology as well as agricultural economic management. Professional associations are one of the important aspects of the region.

Northwest A\&F University and Yangling Vocational and Technical College Agricultural Schools provided a consulting service and actively explored, established and promoted professional peasant farmer associations in Yangling. However, the development of these associations has been problematic. This research examines the problems and achievements of these associations.

\section{Yangling farmer associations}

At present, there are 19 professional farmer associations in Yangling regions. There are more than 2,200 members accounting for 11 percent of the total rural regional households. An overview of these 19 associations

\footnotetext{
* Acknowledgement: The authors acknowledge the financial support of Program for New Century Excellent Talents in University (grant NCET-05-0859) and National Natural Science Foundation of China (grant 70273035).

WANG Zheng-bing, Ph.D., professor, College of Economics and Management, Wuhan Polytechnic University; research fields: agriculture economics, rural sociology.

XU Ting, Ph.D., Entrepreneurship Commercialization and Innovation Center, The University of Adelaide, Australia; research field: agriculture economics.

SUN Hao-jie, Ph.D., lecturer, College of Economics and Management, Chang’an University; research field: agriculture economics.

Allan Rae, professor, Department of Applied and International Economics, Massey University; research field: agriculture policy analysis.
} 
appears in Table 1.

Yangling small scale farmer associations' members have been established for only a short time period (see Table 1).

Table 1 Yangling farmer association distribution

\begin{tabular}{lcccc}
\hline \multirow{2}{*}{ Sorts } & \multicolumn{4}{c}{ Quantity and proportion } \\
\hline \multirow{2}{*}{ Established time } & 1 year & 1.5 year & 2 years & $>2$ years \\
\cline { 2 - 4 } Establishment model & $2(11 \%)$ & $4(21 \%)$ & 1 (5\%) & $12(6 \%)$ \\
\cline { 2 - 4 } & Spontaneity & Government support & Corporation organization & - \\
\hline \multirow{2}{*}{ District covered } & $10(5 \%)$ & $8(4 \%)$ & $1(\%)$ & - \\
\hline \multirow{2}{*}{ Involved industry } & Zone level & Village level & - \\
\cline { 2 - 4 } & $5(2 \%)$ & $14(7 \%)$ & - & - \\
\hline \multirow{2}{*}{ Association scale } & Planting & Stockbreeding & Machining & - \\
\cline { 2 - 4 } & $8(4 \%)$ & $10(5 \%)$ & $1(\%)$ & $>200$ \\
\hline
\end{tabular}

Notes: The planting association includes 4 fruit associations and four vegetable associations; Stockbreeding includes 7 milch cow associations.

\section{Operation of Yangling farmer associations}

\subsection{Frequency of farmer association activities}

Table 2 provides an overview of farmer association activities.

Table 2 Activities organized by associations in 2004

\begin{tabular}{ccccc}
\hline \multirow{2}{*}{ Activities } & $<3$ times & $4-8$ times & $9-15$ times & $>15$ times \\
\cline { 2 - 5 } & $1(5 \%)$ & $9(47 \%)$ & $8(42 \%)$ & $1(5 \%)$ \\
\hline \multirow{2}{*}{ Participating percentage } & $<1 / 3$ & $1 / 3-1 / 2$ & $1 / 2-2 / 3$ & $>2 / 3$ \\
\cline { 2 - 5 } & $1(5 \%)$ & $2(11 \%)$ & $7(37 \%)$ & $9(47 \%)$ \\
\hline
\end{tabular}

\subsection{Content of farmer association activities}

Farmer association activities included the following:

(1) Providing production technology services. At present, most of the associations' primary activities are based around relevant government Departments (Agriculture and Forestry Bureau, the Technology Bureau, Animal Skills Stations, etc.). These employ experts from Northwest A\&F University, and Yangling Vocational and Technical College whose research interests are crop production, breeding management, other areas of technical training and on-site guidance. Activities cover cows, vegetables, non-breeding organizations, the cultivation of technical guidance, fruit trees and the organisation of 30 training events for members and the surrounding populations of more than 3,000 people.

(2) Introducing new varieties and promotion. Yangling Strawberry Association imports, tests and undertakes promotion. It currently has more than 10 kinds of foreign reserves of quality new strawberry varieties and is ready to launch a new variety each year in order to promote the production and income of members and to improve the 
association's influence.

(3) Improving the degree of organization of farmers. Farmer associations are based around the development of important industry sectors in regions such as vegetable cultivation in Nanzhuang, Hujiadi village where vegetable cultivation is the main industry. Here, a vegetable association was established with almost all members being greenhouse growers. In Jiangjiazhai and Guan village of Dazhai town, cattle breeding associations have been established where the main village industry involves milk products. At present, more than 2,200 farmers in the region have joined the association accounting for 11 percent of the total number of households. The association aims to reduce difficulties associated with natural and market farmer risks.

(4) Organize product sales. Sale of agricultural products is a major concern of farmers. An exemplar association associated with generating sales is the Yangling Dairy Association. This association assists in the sale of dairy products to the Guangming dairy companies, Shengguo company, and Baofeng companies. Through consultation between the association and local enterprises, milk prices increased from 0.60 to 0.80 Yuan per 500 grams in 2005, while it also helped farmers to solve the problem of milk arrears. Another successful association, Nanzhuang Vegetable Association, went to Xi'an, Baoji to contact customers and promote sales of vegetables on several occasions. Thus, farmers do not have to engage in solving basic marketing problem but leaving this to their association.

\subsection{Member and non-member farmer comparisons}

Farmer associations provide a variety of services include agricultural marketing, access to market information, the purchase of agricultural resources, pest and disease control advice and comparative data. Thus, the various farmer associations can have a significant impact on farm management through the benefits they provide.

\subsubsection{Comparative economic benefits to farmers}

Based on a random survey of 200 farmers, Table 3 identified the benefits associated with being a member of a farmer association.

Table 3 Association economic benefits

\begin{tabular}{cccc}
\hline \multirow{2}{*}{ Scale } & Decrease & Stable & Increase \\
\cline { 2 - 4 } & $0.84 \%$ & $13 \%$ & $86 \%$ \\
\hline \multirow{2}{*}{ Output } & Decease & Stable & Increase \\
\cline { 2 - 4 } & $0.85 \%$ & $28 \%$ & $71 \%$ \\
\hline \multirow{2}{*}{ Price } & Decease & Stable & Increase \\
\hline \multirow{2}{*}{ Cost } & $0 \%$ & $22 \%$ & Increase \\
\hline \multirow{2}{*}{ Income } & Decease & stable & $32 \%$ \\
\hline
\end{tabular}

Table 4 provides the results of surveys undertaken in 2002, 2003 and 2004. It shows that there were a greater percentage of farmers with higher incomes (>10,000 RMB) who were members of an association than farmers who were not a member of an association. There also were greater improvements in income over the previous year for farmer members than non-members for farmers earning more than 10,000RMB. 
Table 4 Farmer income comparisons

\begin{tabular}{cccccccc}
\hline & & \multirow{2}{*}{$1,000 \mathrm{RMB}$} & $\begin{array}{c}1,001-3,000 \\
\mathrm{RMB}\end{array}$ & $\begin{array}{c}3,001-5,000 \\
\text { RMB }\end{array}$ & $\begin{array}{c}5,001-7,000 \\
\text { RMB }\end{array}$ & $\begin{array}{c}7,001-10,000 \\
\text { RMB }\end{array}$ & $>10,000 \mathrm{RMB}$ \\
\hline \multirow{3}{*}{$\mathrm{M}$} & 2002 & $2.3 \%$ & $4.5 \%$ & $25.0 \%$ & $29.5 \%$ & $13.6 \%$ & $25.0 \%$ \\
& 2003 & $0.0 \%$ & $2.3 \%$ & $9.1 \%$ & $31.8 \%$ & $22.7 \%$ & $34.1 \%$ \\
& 2004 & $0.0 \%$ & $0.0 \%$ & $6.8 \%$ & $6.8 \%$ & $31.8 \%$ & $54.5 \%$ \\
\hline \multirow{3}{*}{$\mathrm{NM}$} & 2002 & $1.3 \%$ & $12.8 \%$ & $30.1 \%$ & $32.7 \%$ & $14.1 \%$ & $9.0 \%$ \\
& 2003 & $1.3 \%$ & $5.8 \%$ & $12.2 \%$ & $42.3 \%$ & $24.4 \%$ & $14.1 \%$ \\
& 2004 & $0.6 \%$ & $3.0 \%$ & $7.8 \%$ & $25.3 \%$ & $42.8 \%$ & $20.5 \%$ \\
\hline
\end{tabular}

Notes: $\mathrm{M}=$ member; $\mathrm{NM}=$ non-member.

3.3.2 Unified control of plant disease and insect pests and livestock and poultry epidemic prevention

Pest and disease control and animal epidemic prevention are important aspects of agricultural production (ZHANG, 2001). Farmers, through the assistance of professional associations, are assisted in the timely detection and treatment of these problems (WANG, 2002). Unified control provided by associations helps to improve prevention efficiency while reducing the costs. For example, members of the Yangling Dairy Association achieved $100 \%$ vaccination rate, milk yield increases of $10 \%$ and the Niudu survival rate increased to $98 \%$. Thus, members benefited. Non-members achieved only a $42 \%$ immunization rate, a Niudu survival rate of $83 \%$, and the adult cattle mortality rate was 2.1 times those of members.

3.3.3 Comparison on agricultural products sales and purchase of agricultural resources

Farmers, through professional associations, can attract more customers, improve the marketing of their products, improve customer negotiations to achieve increased prices for their produce, while achieving acceptable prices for the purchase of agricultural resources. This all leads to improved business profitability and stability. It also means less worry for farmers since prices for their produce are maintained which maintains farmer interest (WANG, 2000). Yangling Vegetable Association and the Yangling Dairy Association made outstanding achievements in this regard. For their members, they achieved an ongoing sales market for farmers' produce as well as price increases for this produce. Association members typically achieved sales prices $15 \%$ greater than non-members while typically paying $10 \%$ less for agricultural supplies than non-members.

\section{Evaluation of Yangling farmer associations}

\subsection{Member and non-member attitudes toward association membership}

A random selection of 200 Yangling farmers found that $60.9 \%$ of farmers expressed a willingness to join an association, $18.6 \%$ had no interest, and $20.6 \%$ were undecided. Members of a number of larger associations (including the Dairy Cattle Breeding Association, Strawberry Association and the Association of Fruit Trees) identified benefits such as technical exchanges, training, the promotion of new varieties, and improved incomes (although a small percentage of members (7.8\%) said that their income had not changed significantly since joining) (GUAN, 2004).

\subsection{Attitude of the government toward associations}

Yangling is classified by the government as an experimental area of professional farmer associations. The Yangling counties, districts, provinces, and municipalities have paid attention to this development. For example, the Yangling district government departments, although providing only limited financial support, provide policy to actively guide the development and construction of associations. Their goals are to expand the size of Associations 
and for them to play a leading role in radiation, the better serve the broad masses of farmers. Several of the larger, stronger potential for the development of the association, a focused strategy of support to the smaller associations provide policy guidance and organize the exchange of experience and technical training.

\subsection{Yangling association leadership}

The survey revealed that farmers hold democratic elections for association leadership. Attitudes toward elections vary depending on association size. Large-scale associations tend to be helped by government and the enthusiasm for leadership of these associations is generally higher than in smaller associations which tend to be more conservative. The Government believes that assistance from associations will reduce market risk and increase farmer income (Mackinnon \& Ish, 2004).

\section{Yangling farmer association problems}

\subsection{Largest obstacles: Small, scattered and uncoordinated}

There are two major problems that confront the various farmer associations. The first problem is that the majority of smaller farmer associations are uninfluential. Most associations have several decades' members. The exceptions are the Yangling Dairy Cattle Breeding Association, the Yangling District Strawberry Association the Yangling District Vegetable Association, and several fruit tree associations which tend to be larger scale.

A second problem is a lack of coordination and overlap across some associations. For example, there are five Dairy Associations and the vegetable and fruit tree associations undertake similar activities. All this results in a failure to coordinate and creates "clutter" in the market.

\subsection{Nature of association is unclear}

Some of the associations act outside their powers (ultra vires). Norms on management can be unclear. Many heads members of associations who do not know what rights they should have and what obligations they should do and what the associations can do and what they can't do.

\subsection{Incomplete organization and management system mechanisms}

It is important that there is a sound organizational structure and management system for the protection of members (Barton, 2004). However, many Yangling farmer associations did not set up in accordance with, for example, the provisions of the General Assembly or the Governing Council. As such, their management systems are unsound. This deprives members of supervision and management decision-making powers and the right to not have a standardized constitution with appropriate rules and regulations.

\subsection{Supervision and restraint mechanisms incomplete}

Farmer associations are non-profit and members do not have any residual claim (members cannot claim as their own any property of an association) (Marion, 1985). Because there is a lack of supervision from overseeing bodies in many associations, some association managers may use their positions to pursue private interests. This make many members have no positivity to take part in associations' activities. So many associations are only shape.

\subsection{Narrow scope of business}

The majority of Yangling farmer associations have a relatively narrow business scope. This can include areas of activity and restrictions in the villages and rural areas, and a focus on Chunnong Hu-particularly those engaged in traditional production rather than commodity production. Some are limited to the provision of quality seeds and seedlings and the dissemination of information. Some provide only individual services such as technical training. Others provide only market development, product marketing, and agricultural product processing services. 


\section{Yangling farmer association countermeasures}

\subsection{Improvements in farmer association democracy}

There is a move toward a democratic management mechanism with "one person, one vote". This approach equates to equality and fairness. However, the "one person, one vote" approach is not the only model. The adoption of a weighted voting system as has been used in the United States is an alternative approach (Poole, Gomis, Igual \& Gimenez, 1998). For example, the total amount of Gujin, in particular, the contribution of prominent members can lead to prominent member's votes carrying more weight-Though their contributions should be limited (for example, having no more than $20 \%$ of the total votes of the right to vote).

A second democratic control mechanism is associated with membership of the general assembly. This is the highest organ of power. Once a year, the members of associations hold a congress with a 2/3 majority of members required.

\subsection{Improvements in farmer association mechanisms for the distribution of interests}

Farmer associations generally adhere to the principle of distribution of profits to members based on the volume of transactions. However, this approach ignores the fact that some members contribute more than others. Thus, the profit distribution should be made on the basis of other factors. These include "distribute dividend by shares" combined with the return of profits and the "one-two systems" format.

\subsection{Clarity of property within the association of property rights}

Generally speaking, farmer association property consists of three parts. The first part is member or investor shares; The second part is the accumulation of inputs; The third part is public property. However, no member can really exercise property ownership. Thus, members only enjoy dividends.

\subsection{Farmers improve the market mechanism of associations}

Farmer associations in general only transact between members. The implementation of closed-end services are not market-oriented and are not available to non-members to provide solidarity. However, with the commodity economy, the development of a market economy and the division of labour, there is a need to deepen cooperation amongst all farmers.

There are shackles of the traditional guidelines of development because in a modern market economy economic organization that cannot be closed from outside market development. Farmers must adhere to market-oriented membership services and the implementation of the commercialization business, and then foreign profits can not be questioned.

\section{Conclusions}

Yangling farmer associations have achieved quickly development than the past. However, there are many problems in their developing, for example, most associations are small, scattered and uncoordinated; The associations' nature of association is unclear; the associations' supervision and restraint mechanisms are incomplete; etc. In order to promote the development of Yangling farmer associations, the farmer associations democracy should be improved, and association mechanisms for the distribution of interests and market mechanism of associations should be done better, and more agricultural economic management experts should help the associations to manage the associations.

(to be continued on Page 64) 